\title{
Management of fractures of anterior mandible with different fixation methods : A single institutional experience
}

\section{Original Article}

\author{
Mahmoud E. Khalifa, Emad F. Essa, Mohammad A. Elshall
}

Department of Oral and Maxillofacial Surgery, Faculty of Dentistry, Tanta University, Egypt

\begin{abstract}
Aim: To evaluate the effectiveness of various internal fixation hardware used for treatment of symphyseal and parasymphyseal mandibular fractures based on a single institution's experience.

Materials and Methods: In this retrospective clinical study, one hundred patients with fractures of the anterior region of the mandible involving both the symphysis and parasymphysis areas were included. All cases were selected from the patients 'records who were treated in the oral and maxillofacial surgery department in a 4 years period extended from May 2013 to May 2017. Surgical admission notes, x-ray reports, operation records, outpatient notes, and complications were recorded. The patients were followed up periodically until a minimum of 6 weeks.

Results: The distribution of fracture pattern was as follows; 53 patients with anterior mandible associated with subcondylar/ condylar fractures, 31 with anterior mandible in association with mandibular angle fractures, and only 16 patients with isolated anterior mandible fracture. The majority of the fractures (40\%) were treated by 2 miniplates, followed by the 3-D miniplates (17\%), equal use (12\% each) of (2 lag screws, 1 lag plus 1 miniplate and 1 reconstruction plate), then 1 lag screw (4\%), and the least was the use of only 1 miniplate $(3 \%)$.

Conclusion: Proper selection of the fixation method for anterior mandibular fractures is essential to guarantee a successful treament and early restoration of function. Each method has its own advantages and disadvantages, and each case should be treated individually based on proper diagnosis and planning.
\end{abstract}

Key Words: Anterior mandible, fixation methods, mandibular fractures.

Received: 28 April 2018, Accepted: 29 July 2018

Corresponding Author: Mohammad A. Elshall, PhD, Department of Oral and Maxillofacial Surgery, Faculty of Dentistry, Tanta University, Egypt, Tel.: 01273314717, E-mail: drelshall@yahoo.com

ISSN: 2090-097X, May 2018, Vol. 9, No.2

\section{INTRODUCTION}

Treatment of mandibular fractures is one of the most frequent forms of therapy provided by oral and maxillofacial surgeons ${ }^{[1]}$. The main goal in treatment of mandibular fractures is to restore the pre-injury form and function, with the least disability and shortest recovery $\operatorname{period}^{[1,2]}$.

The symphysis is one of the most common mandibular fracture sites, with reports of prevalence varying from $9 \%$ to $57 \%$; it is only surpassed by fractures of the condyle or of the angle. Fractures of the symphysis are often associated with the clinical signs of a widened intergonial distance with resultant malocclusion ${ }^{[3,4]}$. However, the anterior mandibular fractures were reported to account for approximately $20 \%$ of mandibular fractures. They are considered relatively common and mostly associated with other indirect fractures especially in the subcondylar and angle regions ${ }^{[5,6]}$.

These fractures result in functional problems (speech, chewing, and swallowing), as well as social problems due to esthetic discrepancies ${ }^{[7]}$. The ideal treatment for mandibular fractures should aim at a perfect anatomical reduction, stable fixation, and satisfactory future function of the mandible with the least possible consequences for the joints ${ }^{[8]}$.

The fractures of anterior mandibular region (symphysis and parasymphysis) are inherently unstable. They do not have two of the stabilizing factors provided to fractures of the posterior tooth-bearing mandible: the interdigitated cusps and fossae of bicuspid and molar teeth and the supporting effects of the masseter and internal pterygoid muscles, which form a natural sling ${ }^{[9]}$.

Various important key points should be considered for the successful management of these fractures that include proper reduction, maintenance of pre-injury occlusion, and early return to function. While the appropriate management will depend on the fracture configuration and severity, and also patient factors such as associated injuries, coexistent lacerations, and residual dentition ${ }^{[6]}$.

Many methods were utilized for the treatment of 
anterior mandibular fractures with either closed or open reduction. They may be treated conservatively with closed reduction and a period of intermaxillary fixation or with open reduction and internal fixation using different forms of hardware such as reconstruction plates, lag screws and miniplates ${ }^{[9,10]}$.

Techniques of open reduction for mandibular fractures have changed and expanded greatly in recent decades, however there is still no consensus regarding the best method of treatment ${ }^{[7,11]}$. The treatment of mandibular fractures by open reduction and internal fixation is very variable. Thus, there are many controversies about the best fixation system in terms of stability, functional recovery, and postoperative complications ${ }^{[12]}$.

Therefore, this study was conducted aiming to evaluate the effectiveness of various internal fixation hardware used for treatment of symphyseal and parasymphyseal (anterior mandible) fractures according to our oral and maxillofacial surgery department experience in dealing with such cases over an extended period of time.

\section{MATERIALS AND METHODS}

One hundred patients with fractures of the anterior region of the mandible involving both the symphysis and parasymphysis areas were included in this retrospective clinical study. All cases were selected from the patients records who were treated in the oral and maxillofacial surgery department in a 4 years period extended from May 2013 to May 2017. Surgical admission notes, x-ray reports, operation records, outpatient notes, and complications were recorded.

The radiological examination included plain anteroposterior (AP), lateral facial radiographs, and orthopantomogram (OPG) for all cases. In cases of simultaneous condylar region and/or angle fractures, an additional CT scan was also obtained and examined (Figure 1).
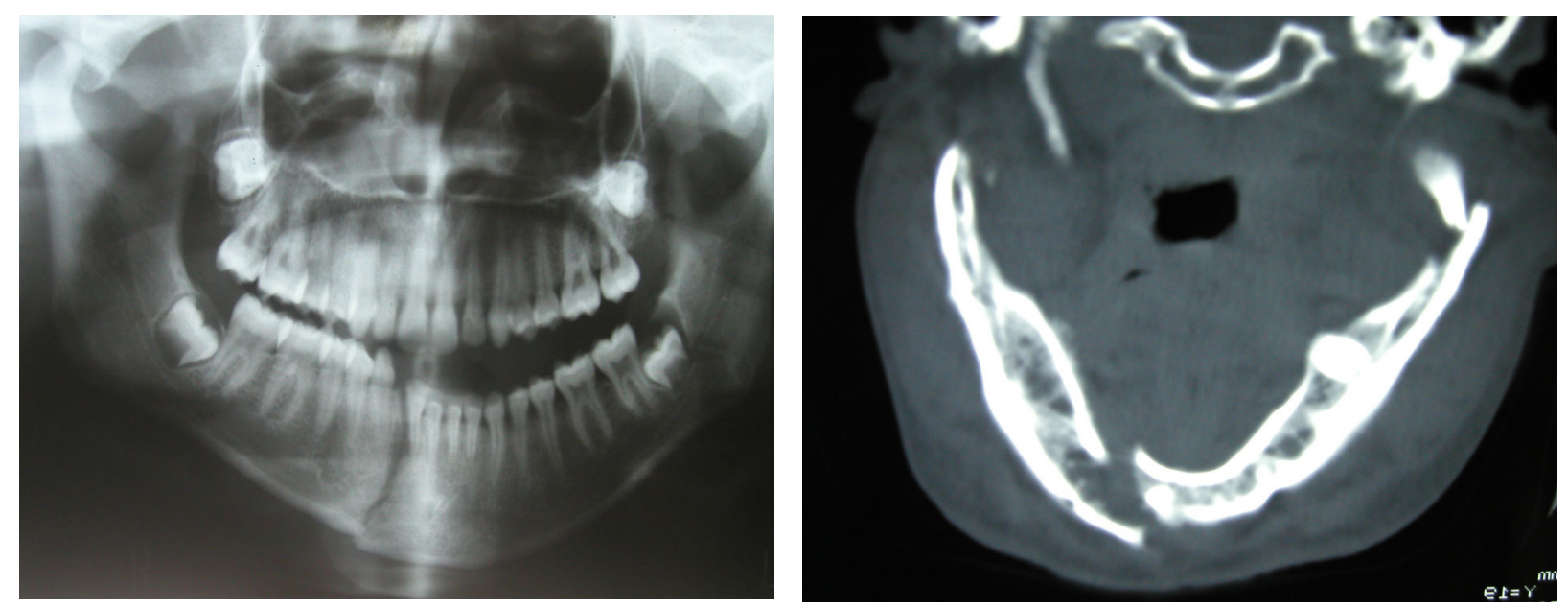

Fig. 1: Preoperative x-rays: a) OPG showing Rt parasymphyseal and Lt angle fractures, b) Axial CT showing Rt parasymphyseal and Lt subcondylar fractures.

A thorough radiological and clinical evaluation of all fractures was made to detect the type and site of fracture, severity of displacement, presence of bony comminution or loss, temporomandibular joint (TMJ) function and integrity, condition of related teeth, extent of pain or discomfort, paresthesia in the lower lip or chin regions, the condition of dental occlusion, affection of the marginal mandibular nerve, and any other associated injury.

Surgical technique

All patients were operated under general anesthesia by nasotracheal intubation. Upper and lower arch bars were first applied to the present dentition. Intermaxillary fixation (IMF) was used temporarily in all cases for open reduction and internal fixation (ORIF) to establish a proper occlusion. The fracture site was accessed intraorally through a vestibular or lip mucosal incision between the mental foramina extending bilaterally between the first premolars, then subperiosteal dissection proceeded to expose the fracture line with preservation of the mental nerves (Fig. 2). The fractured segments were reduced to the proper anatomic position and fixed temporarily using a bone clamp forceps and then the fixation device was applied. 


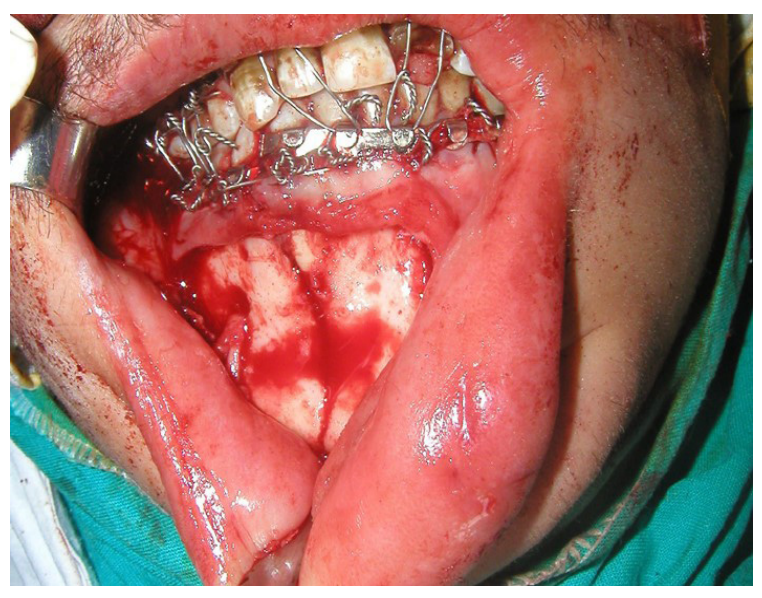

Fig. 2: Intraoral surgical exposure of a Rt parasymphyseal fracture with the patient on a temporary IMF.

Various hardware forms of fixation devices were applied including: two miniplates, two lag screws, 3-D bone plates, one miniplate with a mandibular arch bar as a tension band, one lag screw plus one miniplate at the subapical region of related teeth, one $1.5 \mathrm{~mm}$ (low profile) locking reconstruction plate positioned halfway between the subapical region and the inferior border of the mandible and one lag screw with a mandibular arch bar as a tension band (Figures 3 and 4).

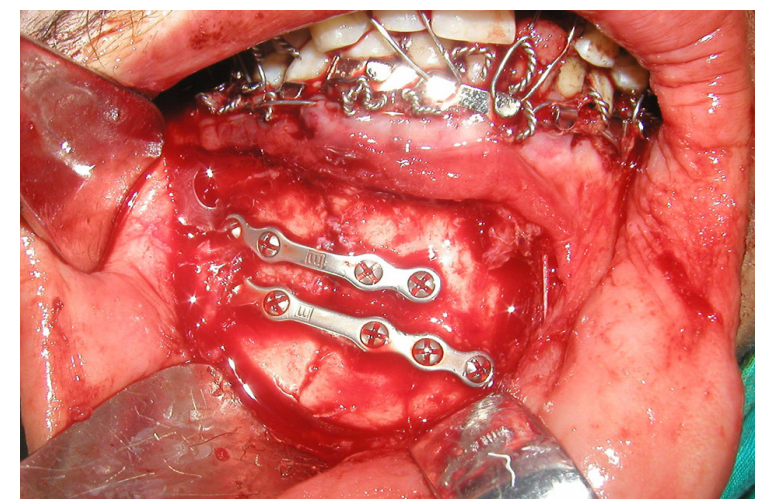

Fig. 3 a

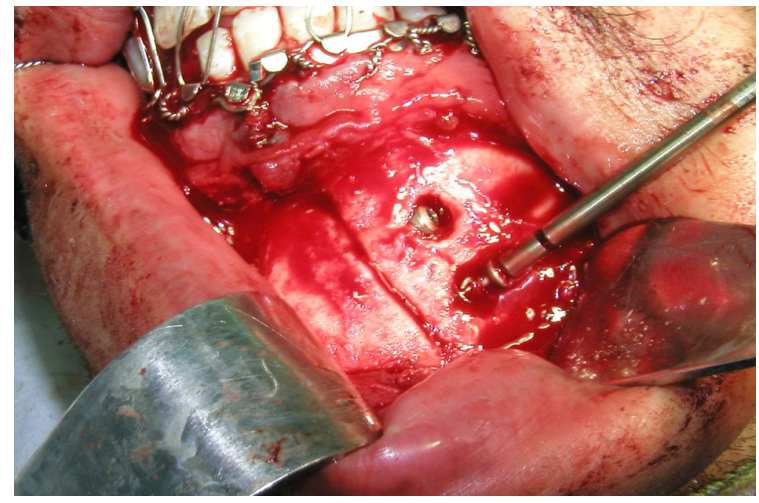

Fig. 3 b

Fig. 3: Intraoperative photographs showing: a) two miniplates, b) two lag screws during tightening of the lower one.

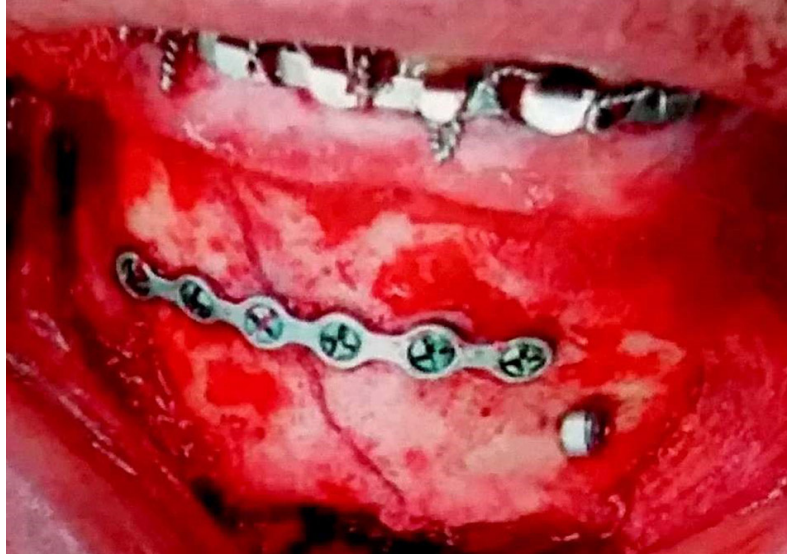

Fig. 4 a

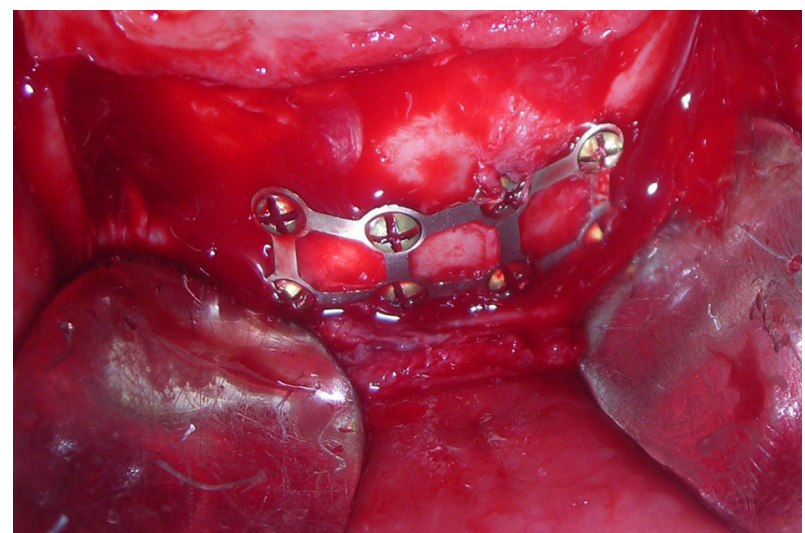

Fig. 4 b

Fig. 4: Intraoperative photographs showing: a) one lag screw at the lower border and one miniplate superior to it, b) 3-D miniplate in a rectangular form.

In 2 cases, where no enough bone was available for the regular application of 2 miniplates due to severe comminution and bone loss, an alternative method of application was used in which one miniplate was applied at the lower margin of the inferior border through degloving of soft tissues in the chin region, while the other was applied labially close to the lower border (Fig 5).

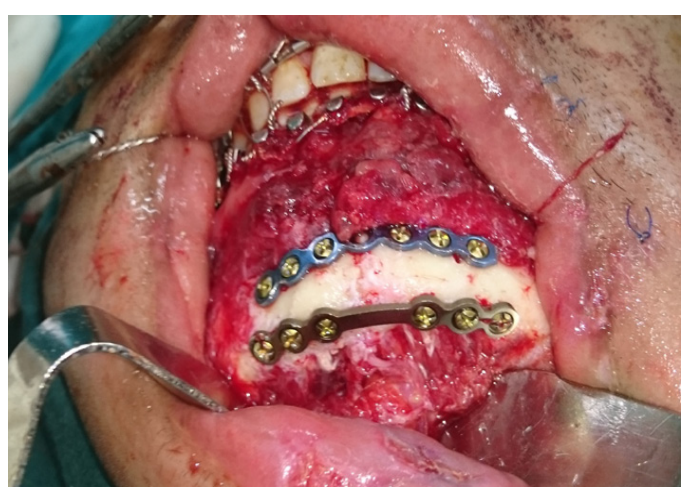

Fig. 5: Intraoperative photograph showing an uncommon technique of applying 2 miniplates; one at the inferior margin of the chin through degloving of soft tissues and the other placed labially close to the lower border. 
After the fixation device has been placed properly with a minimum of 2 screws on each side of the fracture line in case of plate fixation, the IMF was released and the occlusion was carefully checked before wound closure. A double layer watertight closure of the intraoral incision was done with care taken to reattach the mentalis muscle to avoid postoperative sagging of chin. No permanent IMF was utilized in any of the operated patients.

The patients were followed up postoperatively for a minimum of 6 weeks for clinical signs of disturbed occlusion, segment mobility, inferior alveolar nerve (IAN) affection, infection or wound dehiscence. A postoperative OPG and AP or computed tomography scan were obtained to confirm the proper placement of the fixation devices and the anatomic reduction of the fractured segments.

\section{RESULTS}

In this retrospective clinical study, 100 patients with fractures of the anterior mandible were included (78 males and 22 females). The patients' ages ranged from 18-56 with a mean of 35.5 years. The distribution of fracture pattern was as follows; 53 patients with anterior mandible associated with subcondylar/condylar fractures, 31 with anterior mandible in association with mandibular angle fractures, and only 16 patients with isolated anterior mandible fracture.

The types and numbers of fixation devices used in different fracture patterns are shown in table (1). The majority of the anterior mandibular fractures (40\%) were treated by 2 miniplates at the Champy's lines (one 5 or 6 holes plate near the inferior border and a smaller plate of 4 holes above the first by at least $5 \mathrm{~mm}$ in the subapical region). This is followed by the 3-D miniplates (17\%), equal use (12\% each) of ( 2 lag screws, 1 lag plus 1 miniplate and 1 reconstruction plate), then 1 lag screw (4\%), and the least was the use of only 1 miniplate $(3 \%)$

Table 1: Different methods of fixation, type of fracture, and numbers of operated patients.

\begin{tabular}{|c|c|c|c|c|c|c|c|c|}
\hline Fracture type & $\begin{array}{l}2 \text { Miniplates } \\
\text { No. }\end{array}$ & $\begin{array}{l}\text { 3D- Miniplate } \\
\text { No. }\end{array}$ & $\begin{array}{c}2 \text { lag screws } \\
\text { No. }\end{array}$ & $\begin{array}{c}\text { 1Reconstr. } \\
\text { No. }\end{array}$ & $\begin{array}{c}1 \mathrm{Lag}+1 \\
\text { Miniplate } \\
\text { No. }\end{array}$ & $\begin{array}{l}1 \text { Lag screw } \\
\text { No. }\end{array}$ & $\begin{array}{c}1 \\
\text { Miniplate } \\
\text { No. }\end{array}$ & $\begin{array}{l}\text { TOTAL } \\
\text { No. }\end{array}$ \\
\hline $\begin{array}{l}\text { Anterior mandible/ } \\
\text { condyle }\end{array}$ & 23 & 10 & 4 & 6 & 8 & 2 & 2 & 53 \\
\hline $\begin{array}{l}\text { Anterior mandible/ } \\
\text { angle }\end{array}$ & 11 & 5 & 6 & 4 & 3 & 2 & 2 & 31 \\
\hline $\begin{array}{l}\text { Isolated anterior } \\
\text { mandible }\end{array}$ & 6 & 2 & 2 & 2 & 1 & 0 & 0 & 16 \\
\hline Total & 40 & 17 & 12 & 12 & 12 & 4 & 4 & 100 \\
\hline
\end{tabular}

In isolated anterior fractures, 3 cases were treated by only one miniplate in conjunction with a one piece mandibular arch bar that was applied for 6 weeks to act a tension band. Six patients were treated by 2 miniplates, 4 of them using the traditional Champy technique, while in the other 2, the two miniplates were used in which one was applied at the lower margin of the inferior border and the other was applied labially close to the lower border with the use of a continuous arch bar for support and fixation of the dento-alveolar fracture. Two patients treated with 2 lag screws, 2 patients with 3-D miniplates, 2 with one reconstruction plate, one with a single lag plus one miniplate, and no one was treated by only one lag screw.

The clinical and radiographical follow up data were collected for all patients during a minimum of 6 weeks and a maximum of 6 months postoperatively. In 95 patients $(95 \%)$, the data revealed no signs of infection, no problems of wound healing, ecchymosis, or seroma during the follow-up. While in 5 patients (5\%), some related little complications were recorded. In 3 of them (one treated with 2 miniplates and 2 treated with 3-D miniplates), a wound breakdown was developed with exposure of the upper part of the 3-D plate or the smaller plate during the second week postoperatively.

The management of those cases was by using of daily irrigation with normal saline, antiseptic mouthwash, prophylactic antibiotic coverage and keeping good oral hygiene until complete wound healing was achieved in two to three weeks. In another patient treated with lag screw and in other one treated with a reconstruction plate, signs of local infection were developed with slight pus discharge that was attributed to the presence of a devitalized tooth in the fracture line not to the type of the fixation method (Fig. 6). The management of these cases was the same plus extraction of the offending tooth. 


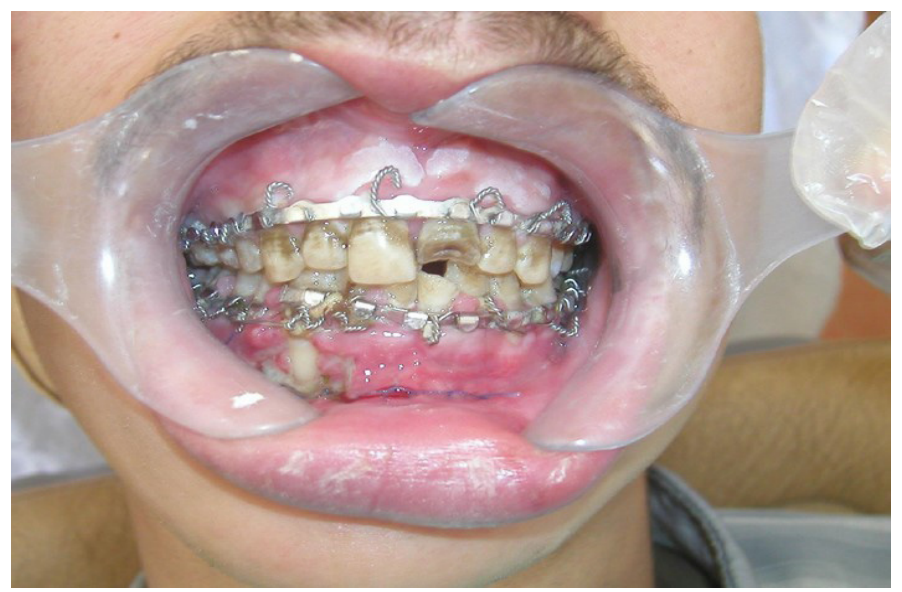

Fig. 6: Postoperative photographs showing wound dehiscence at the surgical site with exposure of a part of the upper miniplate in the 2 nd week

No mobility of the fixed fractured segments was clinically detected in all patients during the succeeding follow up visits. In only 3 patients who were treated by one lag screw and have associated subcondylar fractures, the occlusion was slightly deranged and was corrected by elastic traction and simple selective teeth grinding.
The postoperative neurosensory disturbances of the lower lip or chin regions due to affection of IAN were not detected clinically in any patient. Preoperative paresthesia of the lower lip and chin was found in 7 patients as a result of trauma and segment mobility. Those patients gradually improved postoperatively until regained normal sensation spontaneously between the 4th and 6th week (Table 2).

Table 2: Occurrence of postoperative complications.

\begin{tabular}{|c|c|c|c|c|}
\hline Complication & Patients no. & Fixation type & Fracture type & Cause \\
\hline Wound dehiscence & 3 & $\begin{array}{l}2 \text { miniplates } \\
\text { (1 patient) } \\
\text { 3-D miniplate } \\
\text { (2 patients) }\end{array}$ & Isolated anterior fracture & $\begin{array}{l}\text { Bad oral hygiene. } \\
\text { Noncompliance } \\
\text { with medication. } \\
\text { Frequent lip } \\
\text { manipulation. }\end{array}$ \\
\hline Infection & 2 & $\begin{array}{l}1 \text { lag screw } \\
\text { (1 patient) } \\
\text { Reconstruction } \\
\text { plate (1 patient) }\end{array}$ & $\begin{array}{l}\text { Associated with } \\
\text { angle/subcondylar }\end{array}$ & $\begin{array}{c}\text { Presence of a devitalized } \\
\text { tooth in the fracture line. } \\
\text { Bad oral hygiene. }\end{array}$ \\
\hline Transient malocclusion & 3 & Single lag screw & $\begin{array}{l}\text { Associated with } \\
\text { subcondylar fractures }\end{array}$ & $\begin{array}{l}\text { The use of only one lag. } \\
\text { The associated fractures. }\end{array}$ \\
\hline Segment mobility & 0 & & & \\
\hline NSD* & 0 & & & \\
\hline Total & $8 \quad(8 \%)$ & & & \\
\hline
\end{tabular}

The immediate postoperative radiographs taken within two days showed that the reduction and fixation of the anterior mandibular fractures was good in all cases treated with 2 miniplates, 3-D miniplates, low profile locking reconstruction plates, and two lag screws.
However, the fracture lines' radiolucency were still detected in the other cases treated with either a single lag screw or one miniplate. At 6 weeks postoperatively, the radiographic examination revealed a stability in the reduction and fixation of the fractured bony segments with almost complete healing (Figures 7, 8). 

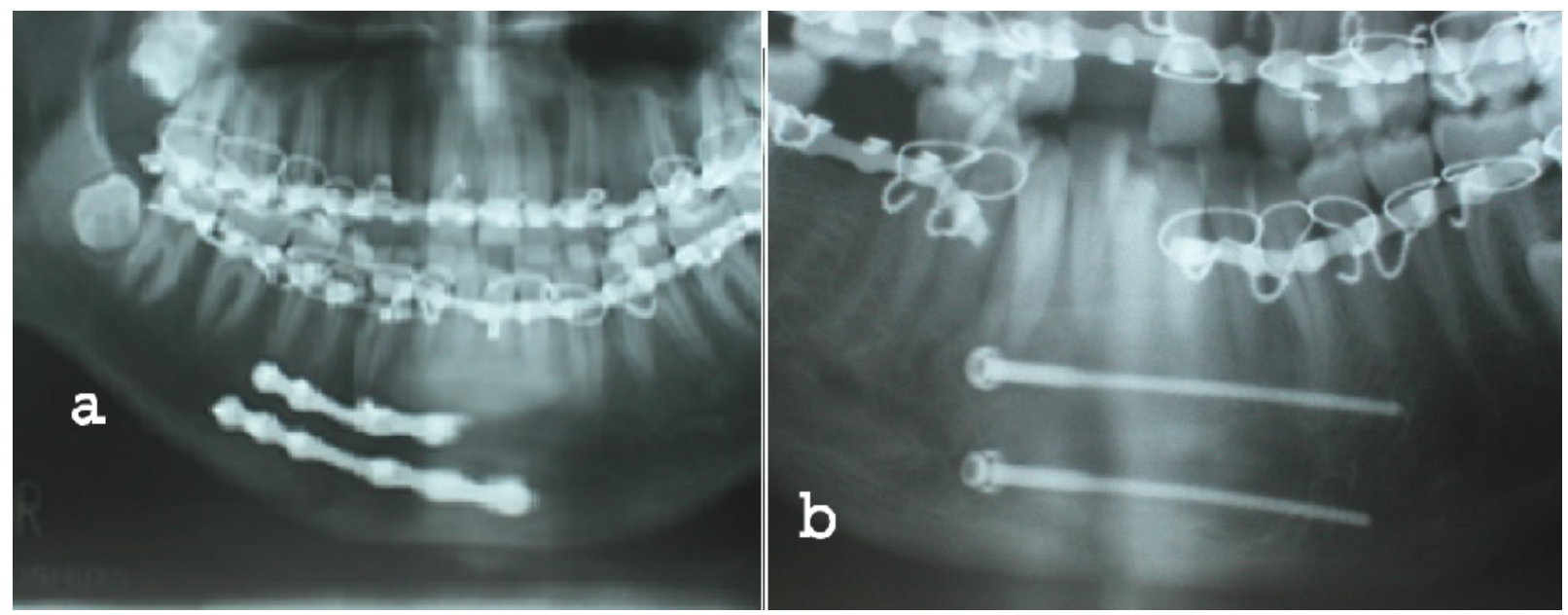

Fig. 7: Immediate postoperative OPGs x-rays of 2 Rt parasymphyseal fractures showing: a) 3-D miniplate, b) one lag screws at the lower border and a miniplate superior to it; with adequate anatomic reduction and proper placement of hardware.
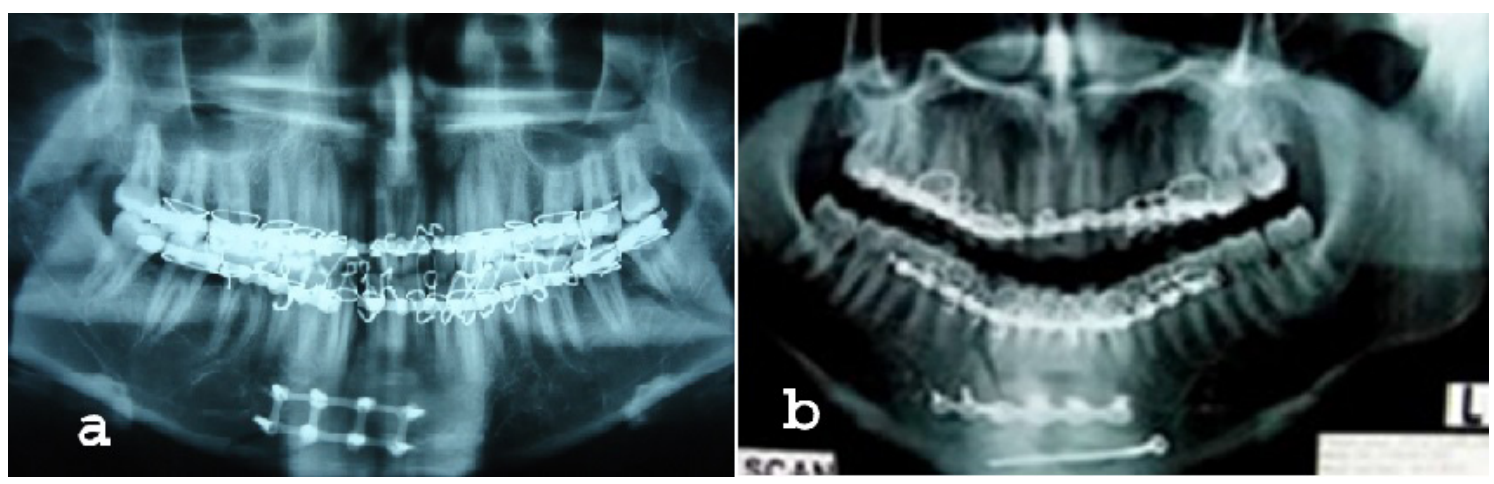

Fig. 8: Six weeks postoperative OPGs x-rays showing: a) 2 miniplates at Rt parasymphyseal fracture, b) 2 lag screws at a symphyseal fracture; with stable reduction and good bony healing.

\section{DISCUSSION}

The anterior mandibular fractures are among the common traumatic injuries received in many trauma centers. Those types of fractures seem to be easily accessed intra-orally with straight forward reduction and fixation due to their reachable anatomical position. However, in some clinical situations such as severely displaced fracures, association with other mandibular fractures commonly at the condylar region, bone comminution and fragment loss, or a considerable time interval until surgical treatment, the management of those fractures with a suitable fixation method may be challenging specially when early mandibular function is required depending upon rigid or semirigid functionally stable fixation method to counteract the strong muscle action.

In the current study, all patients were subjected to treatment of fratures of the anterior mandibular region either isolated or in conjunction with other mandibular fractures. The surgical technique employed for all patients was open reduction and internal fixation (ORIF) without postoperative IMF to early restore the jaw function and to avoid the drawbacks of a closed mouth for several weeks until complete bony healing. This concept of surgical managemnt is supported by many authors and is being currently the prefered method of treatment for mandibular fractures ${ }^{[3,4,7,13]}$.

Fordyes et $a l .{ }^{[13]}$, stated that the ORIF main functional advantages were improved jaw function (in terms of mouth opening and bite force), decreased weight loss, patient comfort, improved pulmonary function, improved speech and oral hygiene, leading to enhanced social interaction, and a decreased number of hospital visits.

In the present study, an intraoral approach was utilized which provides the advantages of eliminated extraoral incision and the resulting scar formation and in the same time is an easy and time saving surgical technique. It is presently considerd the ideal surrgical approach for this anatomically accessible area of the anterior mandible ${ }^{[14-17]}$. 
Currently there are a diversity of metallic hardware used for fixation of jaw fractures. Howevere, the proper selection of the suitable technique is still a matter of debate. Sikora et al. ${ }^{[18]}$, mentioned some factors that may justify the use of one type of fixation over another, such as the patient's age, degree of displacement, the location and level of the fracture line, degree of alteration in occlusion, severity of mandibular involvement, and the experience of the surgeon, as well as the patient preference by providing infromation about the possible advantages and disadvantages of the treatment alternatives.

In the same context, Haug ${ }^{[19]}$ reported that rigid internal fixation with metal plates and screws is being used extensively to fix bone fragments in fracture surgery. The development of titanium as a biocompatible osteosynthesis material has led some researchers to recommend leaving it in situ forever.

The majority of treated cases (40 patients) in this study were done by using of 2 miniplates according to Champy's principles of application in the anterior mandible with a high success rate that's documented in many trauma centers and by many authors ${ }^{[4,7,10,20]}$. On the other hand, the use of a single miniplate was employed in only 3 cases in conjunction with a continuous arch bar as a tension band and it was also successful. This method of fixation seems to provide some advantages in that it reduces the implanted metallic hardware and operation time and also reduces the overall cost. Howevere, it is not a widely accepted technique in this particular area because of fear of inadequate functional stabiltiy. But, Saluja et al. ${ }^{[21]}$ supported this surgical technique in their study and concluded that though miniplates are best placed following Champy's principle, isolated parasymphysis fractures can be managed by putting a single miniplate at the inferior border and utilizing the arch bar as a tension band for 6 weeks. They found no statistically significant difference between this group of treated patients with that technique and the other two groups treated by either 2 miniplates alone or in association with an arch bar.

It is documented that the mandible is normally subjected to a complicated pattern of interacting forces during function in the form of tension forces on its upper border and compression forces on its lower border ${ }^{[3,4]}$. On the other hand, it was also reported that this pattern of forces is true for fractures in the body and angle of the mandible; however, in the case of fractures in the symphyseal and parasymphyseal regions, the opposite situation prevails and a single form of biomechanical behaviour can be expected. It was found that stability is the key factor for the successful treatment of the symphyseal fracture irrespective of the fixation method used ${ }^{[22]}$.

The lag screw used in the present study matches that used by Krenkel ${ }^{[23]}$ who stated that this type has the mechanical advantage of combining with a biconcave washer that transforms the wedging forces underneath the screw head into pressure which the bone is able to tolerate without fracture and thus preventing the lag screw head to penetrate the cortical bone into the underling spongiosa losing its support (anti-crack), so this character had broaden the indications of lag screw in the maxillofacial region.

However, the use of this kind of osteosynthesis depends dolely on the compression between fragments. So, if there is bone comminution, this single stabilizing factor is lost, and the fracture must be treated with bone plates and screws in a neutral position. The direction of fracture line is also of equal importance in that the oblique line is the most suitable for application of this device in a perpindicular direction to the fracture line gaining a maximumu bone $\operatorname{contact}^{[24,25]}$.

In the presnt study, 2 lag screws were used successfully in fixation of fractures of anterior mandible. According to Terheyden et al. ${ }^{[25]}$, the lag screw fixation of those fractures is an exceptionally simple and successful means of rigidly securing bone segments through intraoral approach that enables active use of the mandible during healing but this technique is sensitive and depends on a skillful operator.

In the current study, it is found that in spite the lag screws allow good stability and maximum compression at the fracture line, the use of only one lag in anterior mandibular region is not trusted as it may allow some degree of rotation between segments during function which was recorded in 3 cases treated with a single lag screw and showed some sort of malocclusion which was corrected by using elastic traction and slight selective grinding of related teeth.

Regarding the cases treated with one lag scerw and one miniplate, this method has the advantages of both techniques in which the lag scerw compresses the fractured segments together giving more stabiliy, and the miniplate placed in the subapical reiogn avoiding roots injury and provides additional stability preventing the axial rotation movement around the long axis of the lag screw.

With regard to the use of 3-D plates, de Oliveira et al. ${ }^{[12]}$ stated that there has been far less attention paid to fixation of the mandibular symphysis, and this is true even for the use of 3-D fixation devices in that region.

However, few previous studies ${ }^{[26-30]}$ highlighted the 3-D hardware-related advantages over the conventional miniplates and reconstruction plates, including its easy application, simultaneous stabilization at both superior and inferior borders, simplified adaptation to the bone without distortion or displacement of the fracture, and hence less operative time. They showed also the results of a survey on 104 North American and European $\mathrm{AO} / \mathrm{ASIF}$ surgeons in which only $6 \%$ stated that they use 3-D plates. 
The results of the present study come in agreement with those previous studies in that a shorter operative time was recorded for 3-D plating when compared with other methods of fixation. But there is disagreement regarding the easiness and simplicity of adaptation as this geometric plate design is much more difficult to be perfectly adapted than a linear plate. However, this is in agreement with Jain et al. ${ }^{[31]}$ who stated that a geometric plate is much broader and has to be bent in 3 dimensions, whereas a linear plate has to be bent only in 2 dimensions to be adapted to a curved surface.

The improved biomechanical stability compared with conventional miniplates is another advantage of 3-D plates. The results of this study showed that stability was satisfactory in most cases except those of oblique fractures, which is explained by the encountered difficulty in achieving the principles of 3-D plate fixation in that the horizontal bar should be perpendicular and the vertical bar should parallel the fracture line. This matches the results obtained by de Oliveira et al. ${ }^{[12]}$.

Another limitation of 3-D plates used in this study was the too much hardware material resulting from extra vertical bars incorporated for prevention of the torque forces. However, they offer a suitable and trusted fixation option in most cases with vertically directed fracture lines. This is in accordance with the study of Barde et al. ${ }^{[32]}$, who reported that, the 3-D plate was found to be strong yet malleable, standard in profile, facilitating reduction and stabilization at both tension and compresion borders and giving three dimensional stability at the fracture site, so they are considered a suitable alternative to the conventional Champy`s miniplates.

One of the methods of internal fixation used in this study is a single low profile locking recontsruction plate which provided sufficient stabilty as well as redcution of the amont of hardware. This is in accordance with the results of Hang et al. ${ }^{[33]}$, who stated that the most significant advantges of adding a locking plate system is that it is unneessary for the plate to completely contact the underlying bone in all areas, because when the screws are tightened they lock to the plate therefore fixing the segments without the need to compress the plate to the bone. However, it still have some limitations in the form of increased thickness in comparison to miniplates leading to increased palpability, also increased incidence of wound dehiscence due to its bulk and it does not allow postoperative elastic traction to correct minor occlusal discripancy because of its highly rigid fixation.

Finally, an uncommon fixation approach was used in 2 cases of this study which seems to be very useful and effective in treating specific types of anterior mandibular fractures. We used 2 miniplates with a modified application pattern in which one miniplate was applied at the lower margin of the inferior border through degloving of soft tissues in the chin region, while the other was applied labially close to the lower border. The indication was absence of enough bone available for the classic application due to severe comminution and bone loss.

Based on the collected data from this study, we may recommend some preferred fixation methods of anterior mandible according to fracture type and severity of displacement (Table 3). However, in any case of a single jaw fixation, we do not recommend the use of only one lag screw as this technique is susceptible to displacement during function due to segment rotation around the axis of this screw. The occlusion should be carefully checked before termination of surgery especially when highly rigid fixation methods are used utilizing either the reconstruction plate or 2 lag screws because of the inability to correct the occlusal discrepancy by elastic traction postoperatively.

Table 3: The recommended fixation methods of anterior mandible based on fracture type and severity of displacement.

\begin{tabular}{|c|c|}
\hline Fracture Type & Recommended Fixation Method \\
\hline Mild displacement & - Single miniplate at the lower border with arch bar as a tension band \\
\hline Moderate displacement & $\begin{array}{l}\text { - Single miniplate at the lower border with arch bar as a tension band. } \\
\text { - } 3 \text {-D miniplate } \\
\text {-2 miniplates according to Champy }\end{array}$ \\
\hline Severe displacement & $\begin{array}{l}\text { - } 2 \text { miniplates according to Champy } \\
\text { - } 3 \text {-d miniplate } \\
\text { - Single lag at the lower border and single miniplate at the subapical region } \\
\text { - } 2 \text { lag screws }\end{array}$ \\
\hline Bone comminution & $\begin{array}{l}\text { - Low-profile locking reconstruction plate } \\
\text { - } 2 \text { extended miniplates according to Champy } \\
\text { - } 3 \text {-d extended miniplate }\end{array}$ \\
\hline Bone loss & $\begin{array}{l}\text { - Low-profile locking reconstruction plate } \\
\text { - } 2 \text { miniplates; one at the inferior margin of lower border and the other placed labially close to the } \\
\text { lower border, with arch bar for dentoalveolar fixation }\end{array}$ \\
\hline
\end{tabular}




\section{CONCLUSION}

Proper selection of the fixation method for anterior mandibular fractures is essential to guarantee a successful treament and early restoration of function.

Each method has its own advantages and disadvantages, and each case should be treated individually based on proper diagnosis and planning.

A host of options are availabe with different designs of hardware fixation devices including: Champy's miniplate system, 3-D miniplate, lag scerw, and low profile $(1.5 \mathrm{~mm})$ locking reconstruction plate.

Choice of the suitable hardware, proper application, less invasive surgical procedures, and operator skills and familiarity with some techniques will assure positive results.

\section{ACKNOWLEDGMENT}

We would like to express gratitude to all members of Oral and Maxillofacial Surgery Department, Faculty of Dentistry, Tanta University, for their great help and unlimited support.

\section{CONFLICT OF INTEREST}

There are no conflicts of interest.

\section{REFERENCES}

1. Feller KU, Rechter G, Schneider M, Eckelt U. Combination of micro plate and miniplate for osteosynthesis of mandibular fracture: an experimental study. Int J Oral Maxillofac Surg 2002; 31: 78-83.

2. A1-Belasy FA. A short period of maxillomadibular fixation for treatment of fractures of the mandibular tooth-bearing area. J Oral Maxillofac Surg 2005; 63: 953-6.

3. Peterson LJ, Ellis III E, Hupp JR, Tucker MR. Contemporary oral and maxillofacial surgery. 4th ed. St. Louis: Mosby; 2005.

4. Ji B, Wang C, Liu L, Long J, Tian W, Wang H. A biomechanical analysis of titanium miniplates used for treatment of mandibular symphyseal fractures with the finite element method. Oral Surg Oral Med Oral Pathol Oral Radiol Endod 2010; 109: e21-7.
5. Boole JR, Holtel M, Amoroso P, et al: 5196 mandible fractures amount 4381 active duty army soldiers 1980 to 1998. Laryngoscope 2001; 111: 1691-1696.

6. Zachariades N, Mezitis M, Mourouzis C, et al. Fractures of the mandibular condyle: a review of 466 cases. Literature review, reflections on treatment and proposals. J Craniomaxillofac Surg 2006; 34: 421-432.

7. Sehgal S, Ramanujam L, Prasad K, Krishnappa R. Three-dimensional $\mathrm{v} / \mathrm{s}$ standard titanium miniplate fixation in the management of mandibular fractures - a randomized clinical study. J Craniomaxillofac Surg 2014; 42: 1292-9.

8. Vineeth K, Lalitha RM, Prasad K, Ranganath K, Shwetha V, Singh J. A comparative evaluation between single noncompression titanium miniplate and three dimensional titanium miniplate in treatment of mandibular angle fracture - a randomized prospective study. J Craniomaxillofac Surg 2013; 41: 103-9.

9. Clark WD, Simko EJ. Mandibular fractures. In: Gates GA, ed. Current Therapy in Otolaryngology. Philadelphia: Mosby; 150-152: 1998

10. Farwell D G: Mangement of Symphyseal and Parasymphyseal Mandibular Fractures. Operative Techniques in Otolaryngology 2008; 19: 108-112.

11. Xue AS, Koshy JC, Wolfswinkel EM, Weathers WM, Marsack KP, Hollier Jr LH. A prospective study of strut versus miniplate for fractures of mandibular angle. Craniomaxillofac Trauma Reconstr 2013; 6: 191-6.

12. de Oliveira JCS, Moura LB, de Menezes JDS, Gabrielli MAC, Pereira Filho VA, Hochuli-Vieira E. Three-dimensional strut plate for the treatment of mandibular fractures: a systematic review. Int J Oral Maxillofac Surg (2017), http://dx.doi. org/10.1016/j.ijom.2017.08.009

13. Fordyes AM, Lalani Z, Songra AK, Hilderth AJ, Carton ATM, Hawkesford JE. Intermaxillary fixation is not usually necessary to reduce mandibular fractures. $\mathrm{Br} \mathrm{J}$ Oral Maxillofac Surg 1999; 37: 52-7.

14. Nishioka, G. and Van Sickels, J.: Trans-oral plating of mandibular angle fractures technique. Oral Surg Oral Med Oral Pathol 1988; 66: 531.

15. Undt, G., Kermer, C., Rasse, M. and et al.: 
Trasoral miniplate osteosynthesis of condylar neck fractures. Oral Surg Oral Med Oral Pathol Oral Radiol Endodo. 1999; 88: 534.

16. Schon, R., Gutwald, R., Schramm, A. and et al.: Endoscopy assisted open treatment of condylar fractures of the mandible: Extraoral vs Intraoral approach. Int J Oral MxilloFac Surg. 2002; 31:237.

17. Toma, V., Mathog, R., Toma, R. and Meleca, R.: Transoral vs extraoral reduction of mandible fractures: A comparison of complication rates and other factors. Otolaryngol Head Neck Surg 2003; 128: 215.

18. Sikora M, Olszowski T, Sielski M, Stapor A, Janiszewska-Olszowska J, Chlubek D. The use of the transparotid approach for surgical treatment of condylar fractures-own experience. J Craniomaxillofac Surg 2015; 43: 1961-5.

19. Haug RH: Retention of asymptomatic bone plates used for orthognathic surgery and facial fractures. J Oral Maxillofac Surg 1996; 54: 611.

20. Champy M, Lodde JP, Schmitt R. Mandibular osteosynthesis by miniature screwed plates via a buccal approach. J Maxillofac Surg 1978; 6: 14-21.

21. Saluja H, Kini Y, Mahindra U, Kharkar V, Rudagi $\mathrm{BM}$, Dehane V. A comparative evaluation of different treatment modalities for parasymphysis fractures: a pilot study. Int. J. Oral Maxillofac. Surg. 2012; 41: 906-911.

22. Chiodo TA, Milles M. Use of monocortical miniplates for the intraoral treatment of mandibular fractures. Atlas Oral Maxillofac Surg Clin North Am 2009; 17: 19-25.

23. Krenkel C. Biomechanics and Osteosynthesis of Condylar Neck Fractures of the Mandible. Chicago, IL, Quintessence, 1994.

24. Kallela, I., lizuka, T., Salo, A. and Lindqvist, C.: Lag screw fixation of anterior mandibular fractures using biodegradable polylactide screws: A preliminary report: J Oral MaxilloFac Surg. 1999; 57: 113-119.

25. Terheyden, H., Muhlendyck, C., Feldmann, H. and et al.: The self adapting washer for lag screw fixation of mandibular fractures: finite element analysis and preclinical evaluation. J Cranio MaxilloFac Surg. 1999; 27: 58-64.

26. Gear AJ, Apasova E, Schmitz JP: Treatment modalities for mandibular angle fractures. J Oral Maxillofac Surg 2005; 63: 655-62

27. Farmand M: The 3-dimensional plate fixation of fractures and osteotomies. Facial Plast Surg 1995; 3: 39-45.

28. Feledy J, Caterson EJ, Steger S, et al: Treatment of mandibular angle fractures with a matrix miniplate. A preliminary report.Plast Reconstr Surg 2004; 114: 1711-18.

29. Babu S, Parmar S, Menat M, Raghani, Kapadia $\mathrm{T}$ : Three dimensional miniplate rigid fixation in fracture mandible. Journal of Maxillofacial and Oral Surg 2007; 6: 214-16.

30. Guimond C, Johnson JV, Marchena JM: Fixation of mandibular angle fractures with a $2.0-\mathrm{mm} 3-$ dimensional curved angle strut plate. J Oral Maxillofac Surg 2005; 63: 209-15.

31. Jain MK, Manjunath KS, Bhagwan BK, Shah DK : Comparison of 3-Dimensional and Standard Miniplate Fixation in the Management of Mandibular Fractures J Oral Maxillofac Surg 2010; 68(7): 1568-72.

32. Barde DH, Mudhol A, Ali FM, Madan RS2, Kar S , Ustaad F: Efficacy of 3-Dimensional plates over Champys miniplates in mandibular anterior fractures J Int Oral Health 2014; 6(1): 20-6.

33. Hang R, Street C, and Goltz M: Does plate adaptation affect stability. Abiomechnical comparison of locking and non locking plates. $\mathrm{J}$ oral Maxillofac Sur 2002; 60: 1319-25. 